Review

www.mdpi.com/journal/toxins

\title{
Therapeutic Down-Modulators of Staphylococcal Superantigen-Induced Inflammation and Toxic Shock
}

\section{Teresa Krakauer}

Department of Immunology, Integrated Toxicology Division, United States Army Medical Research Institute of Infectious Diseases, 1425 Porter Street, Fort Detrick, Frederick, MD 21702-5011, USA; E-Mail: Teresa.krakauer@amedd.army.mil; Tel.: +1-301-619-4733; Fax: +1-301-619-2348

Received: 30 June 2010; in revised form: 16 July 2010 / Accepted: 28 July 2010 /

Published: 29 July 2010

\begin{abstract}
Staphylococcal enterotoxin B (SEB) and related superantigenic toxins are potent stimulators of the immune system and cause a variety of diseases in humans, ranging from food poisoning to toxic shock. These toxins bind directly to major histocompatibility complex (MHC) class II molecules on antigen-presenting cells and specific V $\beta$ regions of T-cell receptors (TCR), resulting in hyperactivation of both monocytes/macrophages and T lymphocytes. Activated host cells produce massive amounts of proinflammatory cytokines and chemokines, activating inflammation and coagulation, causing clinical symptoms that include fever, hypotension, and shock. This review summarizes the in vitro and in vivo effects of staphylococcal superantigens, the role of pivotal mediators induced by these toxins in the pathogenic mechanisms of tissue injury, and the therapeutic agents to mitigate the toxic effects of superantigens.
\end{abstract}

Keywords: staphylococcal superantigens; therapeutics; inflammatory mediators; toxic shock; murine models

\section{Staphylococcal Exotoxins as Superantigens}

\subsection{Overview}

Staphylococcus aureus, a ubiquitous gram-positive coccus, produces several exotoxins: staphylococcal enterotoxins A through R (SEA-SER), and toxic shock syndrome toxin 1 (TSST-1), which contribute to its ability to cause disease in humans and laboratory animals [1-8]. These exotoxins bypass the normal mechanism of conventional antigen processing, bind outside the peptide-binding groove of major 
histocompatibility complex (MHC) class II molecules on antigen-presenting cells (APC) and specific V $\beta$ regions of T-cell receptors (TCR), to polyclonally activate T cells [2,9]. Originally known for their pyrogenicity, these bacterial toxins are called "superantigens" because of their potency in stimulating $\mathrm{T}$ cells at picomolar concentrations [2,9]. The dual affinity of staphylococcal superantigens for MHC class II molecules and specific TCR V $\beta$ chains enables these microbial toxins to perturb the immune system and induce high levels of proinflammatory cytokines, chemokines, tissue factor, lytic enzymes, and reactive oxygen species, activating both inflammatory and coagulation pathways [10-19]. Important inflammatory cytokines, tumor necrosis factor $\alpha$ (TNF $\alpha$ ) and interleukin 1 (IL-1) appear early, and in conjunction with other cytokines and chemokines they elicit fever, hypotension, and shock [20]. Interferon (IFN) $\gamma$, a prominant T-helper type 1 (Th1) cytokine, acts synergistically with TNF $\alpha$ and IL-1 to promote immune reaction and tissue injury. IL-2, from superantigen-activated T cells, causes vasodilation and contributes to vascular leak and edema [21]. The chemokines, IL-8, monocyte chemoattractant protein-1 (MCP-1), macrophage inflammatory protein $1 \alpha$ (MIP-1 $\alpha$ ), and MIP-1 $\beta$, are induced directly by SEB or TSST- 1 and selectively activate and direct migration of leukocytes, neutrophils and dendritic cells to sites of tissue injury $[16,17]$. These mediators are pathogenic at high concentrations in vivo and induce fever, organ dysfunction, and death.

\subsection{Physical properties of staphylococcal superantigens}

Staphylococcal enterotoxins (SEs) and TSST-1 are 22 to $30 \mathrm{kD}$ single-chain globular proteins with well-conserved tertiary structures [22]. Based on amino acid sequence alignment, staphylococcal superantigens can be grouped into three subfamilies [6-8,23]. SEA, SED, SEE, SHE, and SEI share the highest sequence homology, between $53 \%$ and $81 \%$. The second group is comprised of SEB, the SECs, and SEG, which are $50 \%$ to $66 \%$ homologous. Finally, TSST- 1 has only $28 \%$ identity with the rest of the SEs as it has a distinct, shorter primary sequence of 194 amino acids with no cysteines and a missing "disulfide loop" commonly found in SEs. This disulfide loop has been proposed to be associated with the emetic properties of SEs, as mutation of residues in this loop eliminated the emetic effects of SEC1. Crystallographic studies of staphylococcal superantigens reveal similarities in the secondary-tertiary structure with two conserved, tightly packed domains. The $N$-terminal $\beta$-barrel domain resembles the oligosaccharide/oligonucleotide-binding (OB) fold found in other unrelated proteins, while the $C$-terminal domain has a $\beta$-grasp motif [22]. The relatively conserved TCR-binding site is located in the shallow groove between these two domains [22,24].

\subsection{Human diseases caused by staphylococcal superantigens}

SEB is the prototypic and most widely studied superantigen and is listed by the Centers for Disease Control and Prevention (CDC) as a category B priority agent because it can be used as an air-borne, food-borne, and water-borne toxic agent. These bacterial toxins have profound effects on the immune system through the action of proinflammatory cytokines which affect local and distant sites of infection. Depending on the dose and route of exposure, SEB and other SEs cause food poisoning, acute and fatal respiratory distress, autoimmune diseases, and toxic shock $[3,7,11,25]$.

Staphylococcal toxic shock syndrome is characterized by fever, hypotension, desquamation of skin, fever, and dysfunction of three or more organ systems [1]. Microbial superantigens are also causative 
agents of autoimmune diseases, as shown in several animal models by their ability to activate APC and normally quiescent, autoreactive T- and B- cells [26-29]. In humans, there is a good correlation between the presence of SEB-specific IgM and arthritis, suggesting a role for this toxin in disease [30]. TSST-1 may also be associated with Kawasaki syndrome, a disease with immunoregulatory abnormalities [31,32]. Psoriasis and atopic dermatitis are autoimmune diseases also linked to staphylococcal and streptococcal colonization of skin and subsequent production of exotoxins like SEA, SEB, SEC, TSST-1, and streptococcal pyrogenic exotoxins [3,29].

\section{Superantigen Binding to Host Cells}

\subsection{Binding to MHC class II}

Superantigens bind to common, conserved elements of MHC class II molecules with relatively high affinity $\left(\mathrm{K}_{\mathrm{d}}=10^{-8}-10^{-7} \mathrm{M}\right)$ [33]. However, each individual toxin exhibits preferential binding to certain MHC isotypes, allowing for different modes of contact for superantigen with MHC class II [33-36]. HLA-DR binds SE and TSST-1 better than HLA-DP or -DQ, and murine IE molecules bind better than IA [37,38]. Crystallographic analysis indicates two distinct sites on MHC class II molecules for superantigen binding. A common, low-affinity binding site is found on the invariant $\alpha$-chain of MHC class II and a high-affinity, zinc-dependent binding site is located on the polymorphic $\beta$-chain [8,22,39-41]. Superantigens in the SEA subfamily can bind to both $\alpha$ and $\beta$ chains of MHC class II, interacting with the OB fold and $\beta$-grasp domain, respectively. This mode of superantigen and MHC class II interaction enables the toxin to bind to both sides of the molecule and cross-link MHC class II on antigen-presenting cells (APC) [40]. Cross-linking allowed SEA to persist on the surface of APC and prolonged their exposure and effects on T cells [42]. SEB and TSST-1 bind only to the generic low-affinity site using the solvent-exposed, hydrophobic core at the $N$-terminal of the superantigen [38,39].

\subsection{Binding to TCR}

The interaction of each toxin with the TCR V $\beta$ chain is unique, as shown by the different V $\beta$ specificities of each superantigen [2,3,9]. Members of the same subgroup interact and stimulate a different but overlapping TCR V $\beta$. For example, SEB stimulates human T cells bearing V $\beta$ 1.1, 3.2, 6.4, 15.1, while another member of this group, SEC1, binds T cells with V $\beta 3.2,6.4,6.9,12,15.1$ [8]. The binding contacts are mostly between the side-chain atoms of the superantigen and the complementarity-determining regions 1 and 2 and the hypervariable region 4 within the V $\beta$ chain. Superantigens bind TCR V $\beta$ with low affinity $\left(\mathrm{K}_{\mathrm{d}}=10^{-4}-10^{-6} \mathrm{M}\right)$, similar to those of conventional MHC/peptide/TCR V $\beta$ interactions. The mitogenic potency of these toxins results from a cooperative interaction such that the superantigen/MHC complex binds the TCR with a higher affinity than toxin alone.

\subsection{Co-stimulatory molecules on host cells}

As with conventional antigens, optimal cell activation requires the expression of co-stimulatory molecules on APC and T cells. These co-stimulatory molecules provide potent signals in addition to TCR engagement and influence T cell differentiation into major subsets of T cells, Th1, Th2, and Th17 cells. Intercellular adhesion molecule (ICAM) on an APC promotes stable cell conjugate formation and is a key 
co-stimulatory signal and adhesion molecule for many cell types [43]. A requirement for IL-2 induction from superantigen-stimulated $\mathrm{T}$ cells is the activation of the CD28-regulated signal transduction pathway [44]. Co-stimulatory pairs of LFA-1/ICAM-1, CD80/CD28 and CD40/CD154 on APC and T cells contribute to modulating immune responses to both conventional antigens and superantigens [43-47]. Other cell surface molecules besides CD11a/ICAM-1, such as CD2 and ELAM, are also required for optimal activation of endothelial cells and T cells by SEB [45].

\section{Immune Activation}

\subsection{Signal transduction}

The main target cells of superantigens are the $\mathrm{CD} 4^{+} \mathrm{T}$ cells and mononuclear phagocytes bearing MHC class II molecules [2,48-51]. Engagement of superantigen with MHC class II and TCR on APC and $\mathrm{T}$ cells, respectively, activates intracellular signaling through receptor clustering. In T-cell clones, phosphatidyl inositol production and intracellular $\mathrm{Ca}^{2+}$ flux were early responses elicited by high concentrations of SEB [51]. Similar to mitogens and other cross-linking ligands of MHC class II, superantigens also activate protein kinase $\mathrm{C}(\mathrm{PKC})$ and protein tyrosine kinase (PTK) pathways [52,53]. Ultimately, activation of transcriptional factors NF- $\kappa \mathrm{B}$ and AP-1 by superantigens results in the expression of proinflammatory cytokines, chemokines, and adhesion molecules on macrophages and T cells [51,53]. Additionally, the mediators produced by these superantigen-activated cells exert potent effects on the immune and cardiovascular system, resulting in multi-organ dysfunction and lethal shock (Figure 1) [54].

Figure 1. Cells and mediators participating in superantigen-induced toxic shock. Reproduced with permission from [54].

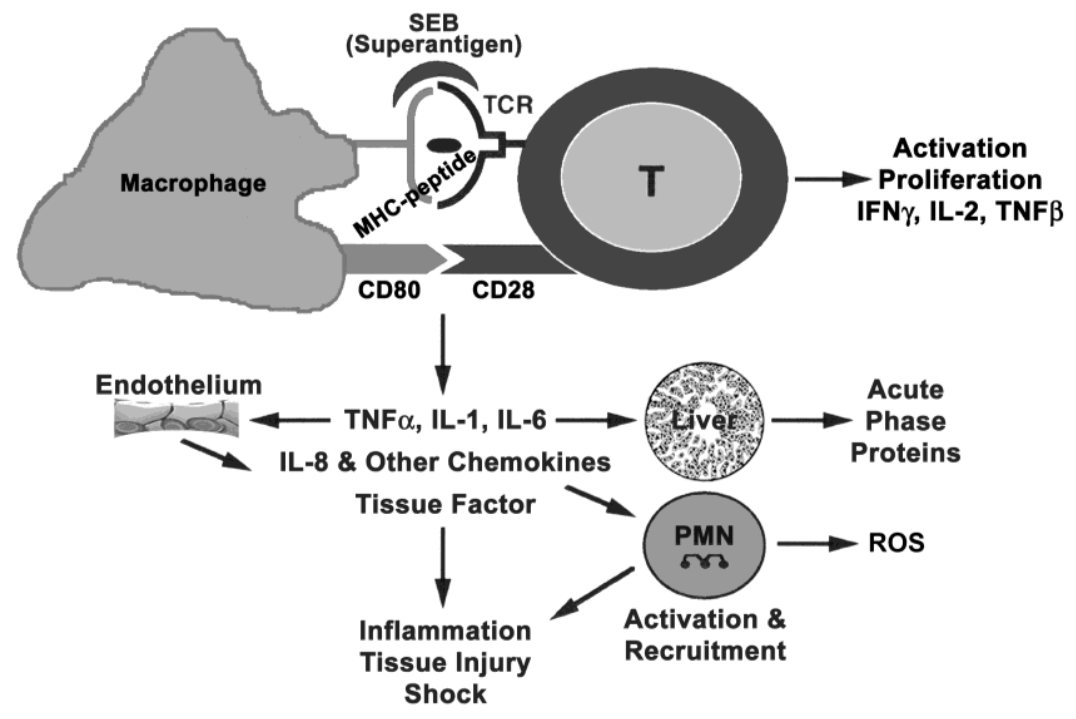

\subsection{In vitro cellular response}

Human peripheral blood mononuclear cells (PBMC) have been used extensively to study the cellular requirements for activation by staphylococcal superantigens, as these cells are sensitive to nanomolar concentrations of toxins. Superantigen-activated PBMC secrete the cytokines IL-1, IL-2, IL-6, IL-12, TNF $\alpha$, TNF $\beta$, IFN $\gamma$; the chemokines, IL-8, MCP-1, MIP-1 $\alpha$, MIP-1 $\beta$ [10-18]. Both monocytes and 
$\mathrm{T}$ cells are required for optimal induction of mediators as cognate interaction of superantigen bound on APC with T cells contributes to the production of these cytokines and chemokines $[14,17,48,49]$. Most of the mediators are induced as early as $5 \mathrm{~h}$ and are present as late as $72 \mathrm{~h}$, whereas superantigen-induced $\mathrm{T}$ cell proliferation appears later, reaching maximum levels at 48 to $72 \mathrm{~h}$. Direct superantigen presentation to T cells in the absence of MHC class II molecules can induce an anergic response [55].

Other cell types responding directly to staphylococcal superantigen include synovial fibroblasts, B cells, mast cells, intestinal myofibroblasts, intestinal and vaginal epithelial cells [56-59]. Superantigen-activated synovial fibroblasts triggered chemokine gene expression, raising the possibility that superantigens can be a causative agent for inflammatory arthritis [57]. Internalized SEB was found in lysosomal compartments of human B cells [42] whereas in an intestinal epithelial cell line, transcytosis of SEB across the cell was observed [58]. The interactions of most superantigens with epithelial and endothelial cells/cell lines are mostly indirect, via the release of IL-1, TNF $\alpha$, and IFN $\gamma$ from superantigen-activated APC and T cells [60,61]. In vivo, SEB was shown to penetrate the gut lining, evoking local and systemic immune response [62]. Vaginal epithelial cells were shown to bind a dodecapeptide of amino acids conserved in all superantigens [59]. In response to SEA but not SEB, human intestinal myofibroblasts elicited IL-6, IL-8, and MCP-1 [63].

\subsection{Signaling and biological effects of proinflammatory mediators}

TNF $\alpha$ and IL-1 have overlapping and similar biological effects. Each can induce the production of other cytokines, chemokines, and cell adhesion molecules with potent immunological and vascular effects [20]. These two proinflammatory cytokines each activate the transcription factor NF- $\kappa \mathrm{B}$ independently in many cell types that include epithelial and endothelial cells and synergizes with IFN $\gamma$ to enhance immunological reactions. The individual and synergistic action of these three cytokines increases the expression of MHC class II, adhesion molecules, and tissue factor on endothelial cells, resulting in disseminated intravascular coagulation. On epithelial cells, these cytokines decrease trans-epithelial resistance and increase ion fluxes and protein transport. The receptors, adaptors, and the signaling molecules used by these three cytokines are vastly different and represent three families of cytokine receptors.

IL-1, an endogenous pyrogen, interacts with IL-1 receptor 1 (IL-1R1) subsequently activating downstream signaling molecules: the adaptor myeloid differentiation factor (MyD88), IL-1R-associated protein kinase (IRAK), and TNF receptor-associated factor 6 (TRAF-6) (Figure 2) [20]. Although toll-like receptors (TLRs) are not used for superantigen signaling, there are many similarities between the intracellular adaptors and signaling molecules used by the IL-1R and TLRs. The TLRs are conserved type 1 transmembrane receptors used by pathogen associated or released molecules to stimulate host innate immune responses [64]. Lipoproteins from gram-negative bacteria and lipopolysaccharide (LPS) from gram positive bacteria use TLR2 and TLR4, respectively, to activate NF- $\kappa \mathrm{B}$ through the MyD88-dependent

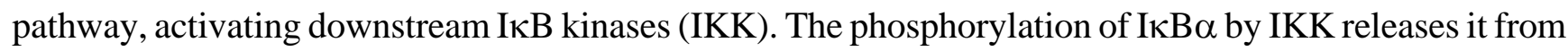

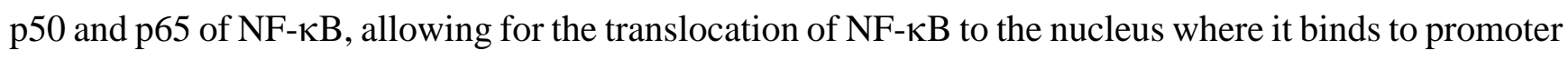
regions of many inflammatory genes $[65,66]$. Activation of $\mathrm{NF}-\kappa \mathrm{B}$ leads to induction of proinflammatory genes as well as antiapoptotic genes. 
Figure 2. Cell receptors, intracellular pathways and signaling molecules used by superantigens and mediators induced by superantigens.

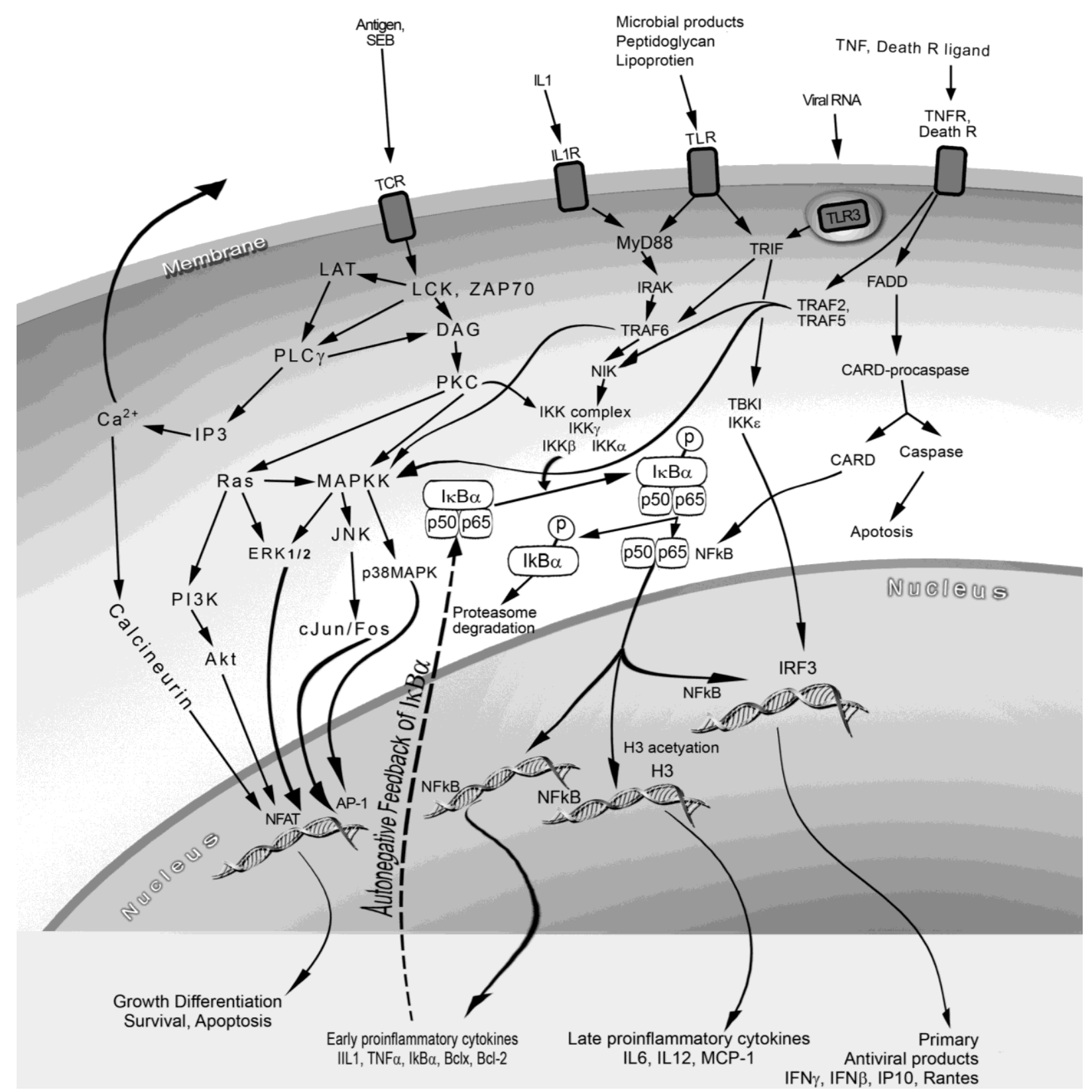

TNF $\alpha$ and TNF $\beta$, bind to TNF receptors (TNFR) and use intracellular TRAFs different from those used by IL-1R or TLR, but ultimately activating NF- $\kappa \mathrm{B}$, resulting in expression of cytokines and co-stimulatory molecules [20,67]. However, the TNFR possesses death domains, commonly present in receptors of the TNFR family, and binding of TNF to TNFR also triggers cell death through caspase activation. IFN $\gamma$ binds to IFN $\gamma \mathrm{R}$, has many immunomodulatory properties different from IL- 1 and TNF, but synergizes with these two cytokines in enhancing immune reactions [68]. IL-6 has some overlapping activities with IL-1 and TNF $\alpha$ [69]. Together and individually, these three cytokines act on the liver to release acute phase proteins, activate apoptopic pathways and decrease liver clearance function.

Various chemokines from superantigen-activated cells attract neutrophils, T cells, dendritic cells, monocytes, and other cell types through seven-transmembrane G-protein-coupled receptors, induce early $\mathrm{Ca}^{++}$flux, and activating phospholipase $\mathrm{C} \beta[20,70]$. Cytokine- and chemokine-activated neutrophils, 
sequestered to sites of tissue injury and inflammation, produce reactive oxygen species (ROS) and proteases contributing to organ dysfunction. This is particularly important in the lung where systemic administration of SEB caused acute lung injury characterized by increased expression of adhesion molecules ICAM-1 and VCAM, increased neutrophils and mononuclear cells infiltrate, endothelial cell injury, and increased vascular permeability [71]. Intranasal delivery of SEB induced a prolong lung injury which was evident even after four days of steroid treatment [72]. Exudates from superantigen-injected air pouches were predominantly neutophils with some macrophages [16]. Endothelial cells surrounding air pouches expressed ICAM-1, TNF $\alpha$, MIP-2 (an IL-8 related protein in mice), MIP-1 $\alpha$, and JE. Thus, systemic release of inflammatory mediators affects multiple organs and cell types resulting in decreased peripheral vascular resistance, multi-organ failure, hypotension, and shock. In vivo, SEB induced V $\beta$ 8-specific $\mathrm{T}$ cell proliferation but these cells were rapidly deleted in the periphery by Fas-FasL-dependent apoptosis [73].

\section{Animal Models}

\subsection{Host response, administration route and dose effects}

Microbial infections are complex diseases where invading pathogens must establish mechanisms to evade host detection and innate inflammatory responses for survival. Bacterial superantigens are among one group of virulence factors released by microbes and contribute to septic complications during infection $[74,75]$. Toxic shock syndrome represents a spectrum and progression of clinical features including multi-organ failure in humans exposed to bacterial toxins and/or concurrent bacterial infection, pathogenic features seemingly absent in most mouse models. In addition, humans are more sensitive to SEB intoxication and low doses are enough to cause lethal shock without the use of synergistic agents. In non-human primates, inhalation of lower, sublethal nanogram doses of aerosolized SEB caused severe incapacitation. TNF $\alpha$ was completely absent, although IL-2 and IL-6 were found in sera of this incapcatitation nonhuman primate model [76]. Microgram levels of aerosolized SEB in monkeys resulted in emesis and diarrhea that developed within $24 \mathrm{~h}$ of exposure, followed by the abrupt onset of lethargy, difficult breathing, hypotension, fever, and finally death from toxic shock [77]. Edema, leukocytic infiltration, and lesions were apparent in lung tissues in this model. The route of SE administration also influenced the pattern of cytokine expression. Intrathymic SEB administration induced a switch from Th1 to Th2 cytokine expression in the spleen [78]. Our own studies indicate that airway exposure was more potent in inducing lethality as lower intranasal (IN) doses can be used compared with just intraperiteonel (ip) injections [79].

\subsection{Emetic response models}

In humans and monkeys, SEs induced an emetic response and toxic shock at submicrogram concentrations [80]. Oral administration of SEB induces activation and expansion of murine $\mathrm{V} \beta 8^{+} \mathrm{T}$-cells in Peyer's patches, accompanied by increased IFN $\gamma$ and IL-2 mRNA expression [81]. The enteric effects of SEs likely resulted from IL-2 release from activated T cells as IL-2 given to cancer patients produces side effects similar to staphylococcal food poisoning. The release of cysteinyl leukotrienes by mast cells and substance $\mathrm{P}$ from sensory neurons was responsible for emesis [56,82]. Recently, rapid release of serotonin 
and intestinal production of 5-hydroxytryptamine was seen in an emetic model using SEA [83]. Mice have no emetic response upon ingestion of high doses of SEs and are not suitable as emetic models.

\subsection{Murine models of toxic shock using potentiating agents}

Investigations of SEs in murine models of toxic shock have relied on potentiation agents to amplify the toxic effects of SEs as mice are poor responders to SEs due to lower affinity of these toxins to mouse MHC class II $[84,85]$. Sensitizing agents such as D-galactosamine (D-gal), actinomycin D, LPS, or viruses are used together with superantigens to induce toxic shock [84-91]. Depending on the injury model and adjunctive agents used, severity of disease may involve different organs and different pattern of mediators. Both D-gal and actinomycin D induced TNF $\alpha$-dependent hepatotoxicity and SEB-induced shock models using these agents encountered much higher levels of TNF $\alpha$ not present when SEB was used alone and liver dysfunction was a prominent feature in these models. IL-2 deficient mice were resistant to SEB-induced shock in D-gal sensitized mice demonstrating the importance of IL-2 besides TNF $\alpha$ [92]. Antibodies to IFN $\gamma$ inhibited SEB-induced weight loss and hypoglycemia but had no effect on mortality [93].

LPS, a cell wall component of gram negative bacteria, is the most frequently used potentiating agent in mouse models of SEB-induced shock. In these models, relatively high doses of SEB were administered via the aerosol, IN or i.p. route, followed by i.p. injections of LPS to induce shock [84,94-97]. LPS naturally synergizes with superantigens to induce the proinflammatory cytokine cascade and a correlation was found between increased serum levels of IL-1, IL-2, TNF $\alpha$, and IFN $\gamma$ with SEB-induced shock [84,94-97]. The shock syndrome induced by superantigens in these models results from the culmination of biological effects of much higher levels of IL-1, TNF $\alpha$, and IFN $\gamma$, not seen when LPS was absent. It is difficult to determine if any one particular cytokine, and at what serum concentration, is required to cause SEB-induced toxic shock, as LPS induces the same proinflammatory cytokines and chemokines (TNF $\alpha$, IL-1, IFN $\gamma$, IL-6, IL-8 and MCP-1) as superantigens. A recent study analyzed the interdependent effects of doses of SEB used alone and together with LPS in different combination of doses on serum levels of cytokine/chemokine in Balb/c mice, the most common mouse strain used in LPS potentiated SEB shock model [98]. In vivo, SEB alone induced only moderate levels of IL-2 and MCP-1 and all mice survived even with a high dose of SEB (100 $\mu \mathrm{g} /$ mouse). LPS ( $80 \mu \mathrm{g} / \mathrm{mouse})$ alone caused $48 \%$ lethality and induced high levels of IL-6 and MCP-1. SEB induced low levels of TNF $\alpha$, IL-1, IFN $\gamma$, MIP-2 and LPS synergized with SEB in the expression of these cytokines as well as those of IL-6 and MCP-1. Importantly, the synergistic action of SEB and LPS resulted in lethal shock and hypothermia not seen in SEB only or low doses of LPS. Cytokine levels by survival status in SEB plus LPS groups revealed significantly higher levels of TNF $\alpha$, IL-6, MIP-2, and MCP-1 in non-survivors early after SEB administration. In addition to these cytokines and chemokines, significantly higher levels of IFN $\gamma$ and IL-2 were observed at later times in non-survivors of toxic shock compared to those in survivors. In this LPS-potentiated SEB-induced shock model, the higher cytokine response, especially at the later time point, was influenced mostly by the LPS dose. Thus, the synergistic action of SEB and LPS promoted early TNF $\alpha$ release and prolonged the release of IL-6, IFN $\gamma$, IL-2, MIP-2, and MCP-1 in non-survivors. Overall, the higher as well as prolonged levels of these key cytokines led to acute mortality, with mice succumbing to toxic shock within $48 \mathrm{~h}$ when LPS was used together with SEB. Although there is a general agreement that Th1 cytokines, typified by IFN $\gamma$, are important in these potentiated models of SEB-induced shock, the role of Th2 cytokines cannot 
be overlooked. IL-10, a prototypic Th2 cytokine, was detected in vivo after repeated superantigen stimulation [99-101]. IL-10-deficient mice showed increase levels of IL-2, IFN $\gamma$, TNF $\alpha$ after SEB stimulation, and they were more susceptible to SEB-induced lethal shock [100]. Repeated superantigen exposure also generated immunosuppressive regulatory $\mathrm{T}$ cells with attendant IL-10 secretion and inhibited IL-2 production [102,103], accompanied by clonal deletion and apoptosis of some of these activated $\mathrm{T}$ cells $[55,103]$.

\subsection{Transgenic mouse models}

The mechanism of SEB intoxication and therapeutic studies were also investigated using transgenic mice with human MHC class II [104-107]. Transgenics respond to much lower doses of toxins due to the higher affinity binding of SEs to human MHC class II molecules and high levels of serum IFN $\gamma$, IL-2, and IL-6 also correlated with mortality [106]. Although TNF $\alpha$ was present in lungs of HLA-DQ8 transgenics exposed to aerosolized SEB, serum TNF $\alpha$ was absent in this study [106]. Pathological lesions in lungs of transgenics, temperature fluctuations, lethality starting later at $96 \mathrm{~h}$, were similar to those in nonhuman primates exposed to lethal doses of SEB. Other investigations [105] suggested that two doses of relatively high amounts of SEB (30 to $100 \mu \mathrm{g} /$ mouse) were necessary to induce toxic shock in these transgenics, and the sensitizing agents D-gal was still required [107].

\subsection{Murine models using only SEB}

A high IN dose of SEB was reported to be lethal in C3H/HeJ, a TLR4-defective mouse strain, but the mechanism of intoxication was unclear [108]. A recent study revealed that this dose of SEB was ineffective in mediating SEB-induced shock, although two low doses of SEB, at least one dose must be delivered by IN, were lethal [79]. This two-hit model required two doses of SEB strategically given $2 \mathrm{~h}$ apart with the first SEB dose delivered by IN and the subsequent dose of SEB administered either IN or by i.p. Increased serum levels of IL-2, IL-6, and MCP-1 accompanied by an early, high concentration of lung MCP-1 was seen in this dual-dosing model [79]. MCP-1, a potent activator and chemotactic factor for $\mathrm{T}$ cells as well as monocytes probably contribute to early leukocyte recruitment into the lung in this IN SEB-induced shock model. The proinflammatory cytokines, IL-1, TNF $\alpha$, and IFN $\gamma$ were found in lungs but not in serum of SEB-exposed C3H/HeJ mice. Pathological lesions, temperature fluctuations, and time course of lethality also resembled those seen in transgenics, nonhuman primates, and humans $[77,106]$.

\section{Therapeutics for Superantigen-Induced Shock}

\subsection{Influence of animal models on efficacy of therapeutics}

None of the existing mouse models completely reproduces all the complex events of human toxic shock syndrome as humans exposed to bacterial toxins often have concurrent bacterial infections. Each toxic shock model described in the previous section revealed the importance of different sets of cytokines and organ injury. In particular, the mouse models using potentiating agents such as actinomycin D, D-gal, or LPS created unrealistically higher levels of certain cytokines such as TNF $\alpha$. As hepatic toxicity is TNF $\alpha$-dependent, drugs designed to inhibit TNF $\alpha$ will have a higher therapeutic impact in models with $\mathrm{TNF} \alpha$-mediated toxicity. However, even nonhuman primate models for human disease in drug efficacy 
testing is no guarantee of reproducibility of therapeutic effectiveness as demonstrated by the cytokine storm elicited in phase 1 trial of the monoclonal antibody to CD28 [109].

Potential therapeutic targets to prevent the toxic effects of SEs include blocking the interaction of SEs with MHC or TCR, or other co-stimulatory molecules; inhibiting signal transduction pathways used by SEs; inhibiting cytokine and chemokine production; and blocking the downstream signaling pathways used by proinflammatory cytokines and chemokines.

\subsection{Antibodies against superantigens}

At present, intravenous immunoglobulins (IVIG) is the only therapeutic available for treating staphylococcal exotoxin-induced shock [110]. Antibody-based therapy targeting direct neutralization of SEB or other superantigens is most suitable at the early stages of exposure before cell activation and release of proinflammatory cytokines. Some of the neutralizing antibodies against one superantigen can cross-react and prevent the biological effects of a diifferent superantigen [111]. Vaccinations with recombinant mutants of SEB, which lack superantigenicity and had attenuated binding to MHC class II, were able to protect mice and monkeys against SEB-induced disease [112].

\subsection{Inhibitors of cell receptor-toxin interaction}

Since the binding regions of SEB to MHC class II and TCR are well-characterized, small overlapping peptides of SEB were used as antagonists to block the initial step of receptor-toxin interactions [113,114]. Conserved peptides corresponding to residues 150-161 of SEB prevented SEA-, SEB-, or TSST-1-induced lethal shock in mice when given intravenously 30 min after an i.p. toxin dose [113]. This segment of SEB is not associated with the classically defined MHC class II or TCR binding domains, but it likely blocks co-stimulatory signals necessary for T-cell activation. However, a subsequent study indicated that these peptides were ineffective inhibitors of SEB-induced effects both in vitro and in vivo [114]. Another recent study with yet a different peptide, dodecapeptide P72, did not bind MHC class II, but inhibited SEA, SEB, and SEC-mediated responses [115].

A different approach using a bi-specific chimeric inhibitor composed of the DR $\alpha 1$ domain of MHC class II and V $\beta$ domain of the TCR specific for SEB connected by a flexible (GSTAPPA) $)_{2}$ linker bound SEB competitively and prevented its binding to MHC class II of APC and TCR on T cells [116]. These chimeric molecules blocked initial cellular activation and IL-2 release in SEB-stimulated PBMC. The drawback of this approach is that individual chimeras have to be constructed for each SE as TCR V $\beta$ domains are different for each SE. Blockade of the CD28 co-stimulatory receptor by its synthetic ligand, CTLA4-Ig, prevented TSST-1-induced proliferation of T cells in vitro as well as lethal toxic shock in vivo [47]. Recently, polyphenols from apple juice were found to inhibit the biological activity of SEA in vitro and SEA was bound to constituents of apple juice [117].

\subsection{Inhibitors of SEB signal transduction}

Blockade of SEB signal transduction pathways represents a more amenable mode of intervention as these events are postexposure and will likely work for other SEs. NF- $\kappa \mathrm{B}$ is an attractive therapeutic target as the activation of NF- $\mathrm{\kappa B}$ leads to the inducible expression of many of the mediators involved in inflammatory diseases. In vitro and in vivo studies have shown that many of the genes (i.e., cell adhesion 
molecules, co-stimulatory molecules, cytokines, chemokines, acute phase proteins, and inducible nitric oxide synthase) that are implicated in superantigen-induced lethal shock contain NF- $\kappa \mathrm{B}$ binding sites in the promotor/enhancer region $[65,66]$. The nuclear import of NF- $\kappa \mathrm{B}$ from cytoplasm upon phosphorylation and removal of $\mathrm{I} \kappa \mathrm{B} \alpha$ allows transcriptional activation of over 100 genes that encode mediators of inflammatory responses and anti-apoptotic genes. Transient interruption of the NF- $\kappa \mathrm{B}$ pathway may therefore be beneficial for superantigen-induced shock. A cell-penetrating cyclic peptide (cSN50) targeting NF- $\kappa B$ nuclear transport attenuated SEB-induced T cell responses and serum inflammatory cytokine [118]. Liver apoptosis and hemorrhagic necrosis and mortality were also reduced in mice given cSN50 before D-gal [119]. Administering cSN50 30 minutes prior to IN SEB in BALB/c mice reduced proinflammatory cytokines and chemokines in the bronchoalveolar space, attenuated neutrophil and monocytes infiltration to the lung and vascular injury [119]. Bortezomib, another NF- $\kappa B$ inhibitor, decreased SEB- induced serum cytokines and chemokines levels but had no effect on mortality and liver necrosis in vivo [120]. Another potent NF- $\kappa \mathrm{B}$ inhibitor is dexamethasone, a well-known immunosuppressive drug used clinically to treat various inflammatory diseases. In vitro, dexamethasone potently inhibited staphylococcal exotoxininduced T-cell proliferation, cytokine release, and activation markers in human PBMC [15,72,97,121]. In vivo, dexamethasone also significantly reduced serum levels of cytokines and protected mice from SEB-induced shock in the two-hit SEB-only model and the SEB plus LPS model [72,97]. Furthermore, dexamethasone attenuated the hypothermic response to SEB in both models of toxic shock and improved survival of mice by $100 \%$ even when administered after SEB.

Other signal transduction inhibitors include those directed against protein kinase $\mathrm{C}$ (PKC) and protein tyrosine kinase. H7, a PKC inhibitor and genistein, a tyrosine kinase inhibitor each blocked TNFa but not IL-1 production from TSST-1-stimulated PBMC [122]. D609, an inhibitor of phospholipase C, which is an upstream activator of $\mathrm{PKC}$, attenuated SE-induced effects both in vitro and in vivo [123,124]. Reduction in lethality was seen in mice treated with D609 and superantigen despite the unaltered high serum level of TNF $\alpha$ [124].

Recently, another FDA-approved immunosuppressive drug, rapamycin was shown to protect SEB-induced shock even when administered $24 \mathrm{~h}$ after SEB [125]. Rapamycin is used clinically to prevent graft rejection in renal transplantation, as it shows less nephrotoxicity than calcineurin inhibitors [126]. Rapamycin inhibited $\mathrm{T}$ cell cytokines and likely interfered with other $\mathrm{T}$ cell signaling pathway induced by SEB.

\subsection{Inhibitors of cytokine induction}

Most therapeutic testing in animal models of SEB-induced shock have targeted proinflammatory cytokines, as there is a strong correlation between toxicity and increased serum levels of these inflammatory mediators, particularly when SEB is used with potentiating agents [93-97]. Neutralizing antibodies against TNF $\alpha$ or soluble TNF receptor 1 prevented SEB-induced lethality, establishing the critical role of TNF $\alpha$ in SEB-induced shock $[86,87]$. The anti-inflammatory cytokine IL-10 blocked the production of IL-1, TNF $\alpha$, and IFN $\gamma$, and reduced lethality to superantigen-induced toxic shock [101].

Another strategy is to attenuate IL-1 release from superantigen-activated cells is to target caspase 1, a proteolytic enzyme that cleaves pro-IL-1 into active IL-1 [20]. The caspase 1 specific inhibitor, Ac-YVAD-cmk, blocked IL-1 and MCP production in superantigen-stimulated PBMC cultures but had no 
effect on other cytokines or T-cell proliferation [127]. A pan-caspase inhibitor, Z-D-CH $2-\mathrm{DCB}$, attenuated the production of IL-1 $\beta$, TNF $\alpha$, IL-6, IFN $\gamma$, MCP, MIP-1 $\alpha$, MIP-1 $\beta$, and inhibited T-cell proliferation in SEB- and TSST-1-stimulated PBMC [127]. In vivo, pan-caspase inhibitor delayed the time of death in the SEB plus LPS model but was ineffective in preventing mortality (unpublished observations). Because IFN $\gamma$ acts in synergy with IL- 1 and TNF $\alpha$, small amounts of IFN $\gamma$ can profoundly affect the potentiation effects with IL-1 and TNF $[20]$. In vivo neutralization of IFN $\gamma$ either protects or harms the host, depending on the mouse model and dose of sensitizing D-gal used [93].

Other drugs tested to block cytokine release from superantigen-activated cells include doxycycline, an antibiotic, and pentoxyfylline, a methylxanthine derivative [95,128]. Doxycycline inhibited SEB-induced proinflammatory cytokines and chemokines and T-cell proliferation in human PBMC [128]. Pentoxyfylline, a phophodiesterase inhibitor, is used clinically to treat peripheral vascular disease. Its interference with intracellular pathways affects leukocyte adhesion and cytokine production. Pentoxyfylline inhibited SEB- or TSST-1-induced toxic shock, as well as cytokine and chemokine release $[15,95]$. Dexamethasone, pentoxyfylline, doxycycline, and rapamycin are FDA-approved drugs used for other indications, and have been in clinical use for many years with a proven safety record. A list of small molecular weight inhibitors effective in blocking SEB-induced shock is shown in Table 1.

Table 1. Small nonpeptide therapeutics for SEB-induced shock.

\begin{tabular}{|c|c|c|}
\hline Pharmacologic agent & Target & Biological effects against SEB \\
\hline $\begin{array}{l}\text { Rapamycin } \\
\text { FDA-approved for } \\
\text { prevention of renal } \\
\text { graft rejection }\end{array}$ & $\begin{array}{l}\text { Immunophilin } \\
\text { FK506BP12 }\end{array}$ & $\begin{array}{l}\text { Blocked SEB-induced MCP-1 and IL-6 in vitro } \\
\text { and in vivo [125]. } \\
\text { Protected mice from lethality even when } \\
\text { administered } 24 \mathrm{~h} \text { after SEB. }\end{array}$ \\
\hline $\begin{array}{l}\text { Dexamethasone } \\
\text { FDA-approved for } \\
\text { treating inflammatory } \\
\text { diseases }\end{array}$ & $\mathrm{NF}-\kappa \mathrm{B}$ & $\begin{array}{l}\text { Inhibited SEB-induced proinflammatory } \\
\text { cytokines and chemokines in PBMC [72] and } \\
\text { adhesion molecules (ICAM, ELAM, VCAM) } \\
\text { on endothelial cells [121]. } \\
\text { Reduced serum levels of cytokines, attenuated } \\
\text { hypothermia due to SEB, improved survival of } \\
\text { mice [72,97]. }\end{array}$ \\
\hline $\begin{array}{l}\text { Pentoxifylline } \\
\text { FDA-approved for } \\
\text { treating peripheral } \\
\text { arterial disease }\end{array}$ & Phosphodiesterase & $\begin{array}{l}\text { Attenuated SEB-induced proinflammatory } \\
\text { cytokines and chemokines in PBMC }[17,97] \text {. } \\
\text { Blocked cytokine release in vivo and prevented } \\
\text { SEB-induced lethal shock in SEB + LPS murine } \\
\text { models [97]. }\end{array}$ \\
\hline Pirfenidone & $\begin{array}{l}\text { Inhibition of TGF } \beta \\
\text { (exact mechanism } \\
\text { unknown) }\end{array}$ & $\begin{array}{l}\text { Inhibited SEB-stimulated cytokines in vitro and } \\
\text { in vivo [96]. } \\
\text { Improved survival of mice [96]. }\end{array}$ \\
\hline Niacinamide & Nitric oxide synthase & $\begin{array}{l}\text { Inhibited serum IL-2 and IFN } \gamma[94] . \\
\text { Prevented death of mice from SEB-mediated } \\
\text { shock [94]. }\end{array}$ \\
\hline D609 & Phospholipase C & $\begin{array}{l}\text { Blocked SEB-stimulated cytokines, chemokines } \\
\text { and proliferation in human PBMC [48]. } \\
\text { Improved survival of mice [103]. }\end{array}$ \\
\hline
\end{tabular}




\subsection{Inhibitors of cytokine signaling}

Blocking the signal transduction pathways used by inflammatory cytokines represents yet another means of inhibiting cellular responses to superantigens. One target is the suppressor of cytokine signal 3 (SOCS3) which is an endogenous stop signal for IFNR-mediated responses and regulates the STAT family of proteins [68]. A cell-penetrating form of SOCS3 protected mice from the lethal effects of SEB and LPS by reducing production of inflammatory cytokines and attenuating liver apoptosis and hemorrhagic necrosis [129].

\section{Summary}

Proinflammatory cytokines act synergistically on multiple cells and organs resulting in cardiovascular derangement, multi-organ failure, and shock seen in SEB-induced diseases. The ability to stop the cytokine cascade and the inflammatory events initiated by cytokines early appears to be critical in preventing toxic shock. However, the tissue damage from cytokine storm lingers and resolution of inflammation, especially in the lungs, appears to be critical in preventing shock.

\section{Acknowledgements}

I thank the Defense Threat Reduction Agency for generous financial support.

\section{Declaim}

The views expressed in this publication are those of the author and do not reflect the official policy or position of the Department of the Army, the Department of Defense or the U.S. Government.

\section{References}

1. Chesney, P.J.; Davis, P.J.; Purdy, W.K.; Wand, P.J.; Chesney, R.W. Clinical manifestations of toxic shock syndrome. JAMA 1981, 246, 741-748.

2. Marrack, P.; Kappler, J. The staphylococcal enterotoxins and their relatives. Science 1990, 248, 705-709.

3. Kotzin, B.L.; Leung, D.Y.M.; Kappler, J.; Marrack, P. Superantigens and their potential role in human disease. Adv. Immunol. 1993, 54, 99-166.

4. Kotb, M. Bacterial pyrogenic exotoxins as superantigens. Clin. Microbiol. Rev. 1995, 8, 411-426.

5. Fraser, J.; Arcus, V.; Kong, P.; Baker, E.; Proft, T. Superantigens-powerful modifiers of the immune system. Mol. Med. Today 2000, 6, 125-132.

6. McCormick, J.K.; Yarwood, J.M.; Schlievert, P.M. Toxic shock syndrome and bacterial superantigens: an update. Ann. Rev. Microbiol. 2001, 55, 77-104.

7. Proft, T.; Fraser, J.D. Bacterial superantigens. Clin. Exp. Immunol. 2003, 133, 299-306.

8. Fraser, J.D.; Proft, T. The bacterial superantigen and superantigen-like proteins. Immunol. Rev. 2008, 225, 226-243. 
9. Choi, Y.; Kotzin, B.; Hernon, L.; Callahan, J.; Marrack, P.; Kappler, J. Interaction of Staphylococcus aureus toxin "superantigens" with human T cells. Proc. Natl. Acad. Sci. USA 1989, 86, 8941-8945.

10. Jupin, C.; Anderson, S.; Damais, C.; Alouf, J.E.; Parant, M. Toxic shock syndrome toxin 1 as an inducer of human tumor necrosis factors and gamma interferon. J. Exp. Med. 1988, 167, 752-761.

11. Parsonnet, J. Mediators in the pathogenesis of toxic shock syndrome: overview. Rev. Infect. Dis. 1989, 11, S263-S269.

12. Fischer, H.; Dohlsten, M.; Andersson, U.; Hedlund, P.; Ericsson, P.; Hansson, J.; Sjogren, H.O. Production of TNF- $\alpha$ and TNF- $\beta$ by staphylococcal enterotoxin A activated human T cells. J. Immunol. 1990, 144, 4663-4668.

13. Trede, N.S.; Geha, R.S.; Chatila, T. Transcriptional activation of IL-1 beta and tumor necrosis factor-alpha genes by MHC class II ligands. J. Immunol. 1991, 146, 2310-2315.

14. See, R.H.; Kum, W.W., Chang, A.H.; Goh, S.H.; Chow, A.W. Induction of tumor necrosis factor and interleukin-1 by purified staphylococcal toxic shock syndrome toxin 1 requires the presence of both monocytes and T lymphocytes. Infect. Immun. 1992, 60, 2612-2618.

15. Krakauer, T. Inhibition of toxic shock syndrome toxin-induced cytokine production and $\mathrm{T}$ cell activation by interleukin 10, interleukin 4, and dexamethasone. J. Infect. Dis. 1995, 172, 988-992.

16. Tessier, P.A.; Naccache, P.H.; Diener, K.R.; Gladue, R.P.; Neotem, K.S.; Clark-Lewis, I.; McColl, S.R. Induction of acute inflammation in vivo by staphylococcal superantigens. II. Critical role for chemokines, ICAM-1, and TNF-alpha. J. Immunol. 1998, 161, 1204-1211.

17. Krakauer, T. The induction of CC Chemokines in human peripheral blood mononuclear cells by staphylococcal exotoxins and its prevention by pentoxifylline. J. Leukco. Biol. 1999, 66, 158-164.

18. Krakauer, T. Immune response to staphylococcal superantigens. Immunol. Res. 1999, 20, 163-173.

19. Mattsson, E.; Herwald, H.; Egsten, A. Superantigen from Staphylococcus aureus induce procoagulant activity and monocyte tissue factor expression in whole blood and mononuclear cells via IL-1ß. J. Thromb. Haemost. 2003, 1, 2569-2575.

20. Krakauer, T.; Vilcek, J.; Oppenheim, J.J. Proinflammatory cytokines: TNF and IL-1 families, chemokines, TGFß and others. In Fundamental Immunology, 4th ed.; Paul, W., Ed.; LippincottRaven: Philadelphia, PA, USA, 1998; pp. 775-811.

21. Vial, T.; Descotes, J. Immune-mediated side-effects of cytokines in human. Toxicology 1995, 105, 31-57.

22. Papageorgiou, A.C.; Acharya, K.R. Microbial superantigens: from structure to function. Trends Microbiol. 2000, 8, 369-375.

23. Monday, S.R.; Bohach, G.A. Properties of Staphylococcus aureus enterotoxins and toxic shock syndrome toxin-1. In The Comprehensive Sourcebook of Bacterial Protein Toxins; Alouf, J.E., Freer, J.H., Eds.; Academic: London, UK, 1999; pp. 589-610.

24. Kappler, J.W.; Herman, A.; Clements, J.; Marrack, P. Mutations defining functional regions of the superantigen staphylococcal enterotoxin B. J. Exp. Med. 1992, 175, 387-396.

25. Holmberg, S.D.; Blake, P.A. Staphylococcal food poisoning in the United States. New facts and old misconceptions. JAMA 1984, 251, 487-489.

26. Abdelnour, A.T.; Bremell, T.; Tarkowski, A. TSST-1 contributes to the arthritogenecity of Staphylococcus aureus. J. Infect. Dis. 1994, 170, 94-99. 
27. Schwab, J.H.; Brown, R.R.; Anderle, S.K.; Schlievert, P.M. Superantigen can reactivate bacterial cell wall-induced arthritis. J. Immunol. 1993, 150, 4151-4159.

28. Brocke, S.; Hausmann, S.; Steinmam, L.; Wucherpfennig, K.W. Microbial peptides and superantigens in the pathogenesis of autoimmune diseases of the central nervous system. Semin. Immunol. 1998, 10, 57-67.

29. Yarwood, J.M.; Leung, D.Y.; Schlievert, P.M. Evidence for the involvement of bacterial superantigens in psoriasis, atopic dermatitis, and Kawasaki syndrome. FEMS Microbiol. Lett. 2000, 192, 1-7.

30. Origuchi, T.; Eguchi, K.; Kawabe, Y.; Yamashita, I.; Mizokami, A.; Ida, H.; Nagataki, S. Increased levels of serum IgM antibody to staphylococcal enterotoxin B in patients with rheumatoid arthritis. Ann. Rheum. Dis. 1995, 54, 713-732.

31. Meissner, H.C.; Leung, D.Y.M. Superantigens, conventional antigens and the etiology of Kawasaki syndrome. Pediatr. Infect. Dis. J. 2000, 19, 91-94.

32. Meissner, H.C.; Leung, D.Y.M. Kawasaki Syndrome: Where Are the Answers? Pediatrics 2003, 112, 672-676.

33. Mollick, J.A.; Chintagumpala, M.; Cook, R.G.; Rich, R.R. Staphylococcal exotoxin activation of T cells. Role of exotoxin-MHC class II binding affinity and class II isotype. J. Immunol. 1991, 146, 463-468.

34. Herrmann, T.; Acolla, R.S.; MacDonald, H.R. Different staphylococcal enterotoxins bind preferentially to distinct MHC class II isotypes. Eur. J. Immunol. 1989, 19, 2171-2174.

35. Herman, A.; Croteau, G.; Sekaly, R.P.; Kappler, J.; Marrack, P. HLA-DR alleles differ in their ability to present staphylococcal enterotoxins to T cells. J. Exp. Med. 1990, 172, 709-712.

36. Chintagumpala, M.M.; Mollick, J.A.; Rich, R.R. Staphylococcal toxins bind to different sites on HLA-DR. J. Immunol. 1991, 147, 3876-3882.

37. Scholl, P.; Sekaly, R.; Diez, A.; Glimcher, L.; Geha, R. Binding of toxic shock syndrome toxin-1 to murine major histocompatibility complex class II molecules. Eur. J. Immunol. 1990, 20, 1911-1916.

38. Thibodeau, J.; Cloutier, I.; Lavoie, P.M.; Labrecque, N.; Mourad, W.; Jardetzky, T.; Sekaly, R.P. Subsets of HLA-DR1 molecules defined by SEB and TSST-1 binding. Science 1994, 266, 1874-1878.

39. Ulrich, R.G.; Bavari, B.; Olson, M.A. Staphylococcal enterotoxins A and B share a common structural motif for binding class II major histocompatibility complex molecules. Nat. Struct. Biol. 1995, 2, 554-560.

40. Hudson, K.R.; Tiedemann, R.E.; Urban, R.G.; Lowe, S.C.; Strominger, J.L.; Fraser, J.D. Staphylococcal enterotoxin A has two cooperative binding sites on major histocompatibility complex class II. J. Exp. Med. 1995, 182, 711-720.

41. Tiedemann, R.E; Urban, R.J.; Strominger, J.L.; Fraser, J.D. Isolation of HLA-DR1.(staphylococcal enterotoxins A)2 trimers in solution. Proc. Natl. Acad. Sci. USA 1995, 92, 12156-12159.

42. Pless, D.D.; Ruthel, G.; Reinke, E.K.; Ulrich, R.G.; Bavari, S. Persistence of zinc-binding bacterial superantigens at the surface of antigen-presenting cells contributes to the extreme potency of these superantigens as T-cell activators. Infect. Immun. 2005, 73, 5358-5366.

43. Linsley, P.S.; Ledbetter, J.A. The role of the CD28 receptor during T cell responses to antigen. Ann. Rev. Immunol. 1993, 11, 191-212. 
44. Fraser, J.; Newton, M.; Weiss, A. CD28 and T-cell antigen receptor signal transduction coordinately regulates interleukin 2 gene expression in response to superantigen stimulation. J. Exp. Med. 1992, $175,1131-1134$.

45. Krakauer, T. Costimulatory receptors for the superantigen staphyloccoccal enterotoxin B on human vascular endothelial cells and T cells. J. Leukco. Biol. 1994, 56, 458-463.

46. Mehindate, K.; al-Daccak, R.; Damdoumi, F.; Mourad, W. Synergistic effect between CD40 and class II signals overcomes the requirement for class II dimerization in superantigen-induced cytokine gene expression. Eur. J. Immunol. 1996, 26, 2075-2080.

47. Saha, B.; Jaklic, B.; Harlan, D.M.; Gray, G.S.; June, C.H.; Abe, R. Toxic shock syndrome toxin-1 induced death is prevented by CTLA4Ig. J. Immunol. 1996, 157, 3869-3875.

48. Carlsson, R.; Fischer, H.; Sjogren, H.O. Binding of staphylococcal enterotoxin A to accessory cells is a requirement for its ability to activate human T cells. J. Immunol. 1998, 140, 2484-2488.

49. Tiedemann, R.E.; Fraser, J.D. Cross-linking of MHC class II molecules by staphylococcal enterotoxin $\mathrm{A}$ is essential for antigen-presenting cell and T cell activation. J. Immunol. 1996, 157, 3958-3966.

50. Anderson, M.R.; Tary-Lehmann, M. Staphylococcal enterotoxin-B-induced lethal shock in mice is T-cell-dependent, but disease susceptibility is defined by the non-T-cell compartment. Clin. Immunol. 2001, 98, 85-94.

51. Chatila, T.; Geha, R.S. Signal transduction by microbial superantigens via MHC class II molecules. Immunol. Rev. 1993, 131, 43-59.

52. Chatila, T.; Wood, N.; Parsonnet, J.; Geha, R.S. Toxic shock syndrome toxin-1 induces inositol phospholipid turnover, protein kinase $\mathrm{C}$ translocation, and calcium mobilization in human $\mathrm{T}$ cells. J. Immunol. 1988, 140, 1250-1255.

53. Scholl, P.R.; Trede, N.; Chatila, T.A.; Geha, R.S. Role of protein tyrosine phosphorylation in monokine induction by the staphylococcal superantigen toxic shock syndrome toxin-1. J. Immunol. 1992, 148, 2237-2241.

54. Krakauer, T. Small nonpeptide inhibitors of staphylococcal superantigen-induced cytokine production and toxic shock. In Superantigens: Molecular Basis for Their Role in Human Diseases; Kotb, M., Fraser, J.D., Eds.; ASM: Washington, DC, USA, 2007; pp. 229-224.

55. Hewitt, C.; Lamb, J.; Hayball, J.; Hill, M.; Owen, M.; O’Hehir, R. MHC Independent clonal T cell anergy by direct interaction of staphylococcal enterotoxin B with the T-cell antigen receptor. J. Exp. Med. 1992, 175, 1493-1499.

56. Scheuber, P.H.; Denzlinger, C.; Wilker, D.; Beck, G.; Kepper, D.; Hammer, D.K. Staphylococcal enterotoxin $\mathrm{B}$ as a nonimmunological mast cell stimulus in primates: the role of endogenous cysteinyl leukotrienes. Int. Arch. Allergy Appl. Immunol. 1987, 82, 289-291.

57. Mourad, W.; Mehindate, K.; Schall, T.; McColl, S. Engagement of MHC class II molecules by superantigen induces inflammatory cytokine gene expression in human rheumatoid fibroblast-like synoviocytes. J. Exp. Med. 1992, 175, 613-616.

58. Hamad, A.R.; Marrack, P.; Kappler, J.W. Transcytosis of staphylococcal superantigen toxins. J. Exp. Med. 1997, 185, 1447-1454. 
59. Peterson, M.L.; Ault, K.; Kremer, M.J.; Klingelhutz, A.J.; Davis, C.C.; Squier, C.A.; Schlievert, P.M. The innate immune system is activated by stimulation of vaginal epithelial cells with Staphylococcus aureus and toxic shock syndrome toxin 1. Infect. Immun. 2005, 73, 2164-2174.

60. McKay, D.M. Bacterial superantigens: provocateurs of gut dysfunction and inflammation? Trends Immunol. 2001, 22, 497-501.

61. Krakauer, T. Stimulant-dependent modulation of cytokines and chemokines by airway epithelial cells: cross- talk between pulmonary epithelial and peripheral blood mononuclear cells. Clin. Diagn. Lab. Immunol. 2002, 9, 126-131.

62. Shupp, J.W.; Jett, M.; Pontzer, C.H. Identification of a transcytosis epitope on staphylococcal enterotoxins. Infect. Immun. 2002, 1029, 313-318.

63. Pinchuk, I.V.; Beswick, E.J.; Saada, J.I.; Suarez, G.; Winston, J.; Mifflin, R.C.; Di Mari, J.F.; Powell, D.W.; Reyes, V.E. Monocyte chemoattractant protein-1 production by intestinal myofibroblasts in response to staphylococcal enterotoxin A: relevance to staphylococcal enterotoxigenic disease. J. Immunol. 2007, 178, 8097-8106.

64. Takeuchi, O.; Akira, S. Pattern recognition receptors and inflammation. Cell 2010, 140, 805-820.

65. Vallabhapurapu, S.; Karin, M. Regulation and function of NF- $\kappa$ B transcription factors in the immune system. Annu. Rev. Immunol. 2009, 27, 693-733.

66. Krakauer, T. Molecular therapeutic targets in inflammation: cyclooxygenase and NF-кB. Curr. Drug Targets Inflamm. Allergy 2004, 3, 317-324.

67. Keystone, E.C.; Ware, C.F. Tumor necrosis factor and anti-tumor necrosis factor therapies. J. Rheumatol. 2010, 85, 27-39.

68. Dunn, G.P.; Koebel, C.M.; Schreiber, R.D. Interferons, immunity and cancer immunoediting. Nat. Rev. Immunol. 2006, 6, 836-848.

69. Wang, X.; Lupardus, P.; LaPorte, S.L.; Garcia, K.C. Structural biology of shared cytokine receptors. Annu. Rev. Immunol. 2009, 27, 27-60.

70. Luster, A.D.; Alon, R.; von Andrian, U.H. Immune cell migration in inflammation: present and future therapeutic targets. Nat. Immunol. 2005, 6, 1182-1190.

71. Neumann, B.; Engelhardt, B.; Wagner, H.; Holzmann, B. Induction of acute inflammatory lung injury by staphylococcal enterotoxin B. J. Immunol. 1997, 158, 1862-1871.

72. Krakauer, T.; Buckley, M.; Huzella, L.M.; Alves, D. Critical timing, location and duration of glucocorticoid administration rescues mice from superantigen-induced shock and attenuates lung injury. Int. Immunopharmacol. 2009, 9, 1168-1174.

73. Ettinger, R.; Panka, D.J.; Wang, J.K.; Stanger, B.Z.; Ju, S.T.; Marshak-Rothstein, A. Fas ligandmediated cytotoxicity is directly responsible for apoptosis of normal CD4+ T cells responding to a bacterial superantigen. J. Immunol. 1995, 154, 4302-4308.

74. Proft, T.; Sriskandan, S.; Yang, L.; Fraser, J.D. Superantigens and streptococcal toxic shock syndrome. Emerg. Infect. Dis. 2003, 9, 1211-1218.

75. Sriskandan, S.; Unnikrishnan, M.; Krausz, T.; Dewchand, H.; Van Noorden, S.; Cohen, J.; Altmann, D.M. Enhanced susceptibility to superantigen-associated streptococcal sepsis in human leukocyte antigen-DQ transgenic mice. J. Infect. Dis. 2001, 184, 166-173.

76. Krakauer, T.; Pitt, L.; Hunt, R.E. Detection of IL-6 and IL-2 in serum of rhesus monkeys exposed to a nonlethal dose of staphylococcal enterotoxin B. Mil. Med. 1997, 162, 612-615. 
77. Mattix, M.E.; Hunt, R.E.; Wilhelmsen, C.L.; Johnson, A.J.; Baze, W.B. Aerosolized staphylococcal enterotoxin B-induced pulmonary lesions in rhesus monkeys (Macaca mulatta). Toxicol. Pathol. 1995, 23, 262-268.

78. Goettelfinger, P.; Lecerf, F.; Berrih-Aknin, S.; German-Fattal, M. Cytokine deviation induced by intrathymic injection of staphylococcal enterotoxin B (SEB). Eur. Cytokine Netw. 2001, 12, 487-500.

79. Huzella, L.M.; Buckley, M.J.; Alves, D.A.; Stiles, B.G.; Krakauer, T. Central roles for IL-2 and MCP-1 following intranasal exposure to SEB: A new mouse model. Vet. Res. Sci. 2009, 86, 241-247.

80. Hodoval, L.F.; Morris, E.L.; Crawley, G.J.; Beisel, W.R. Pathogenesis of lethal shock after intravenous staphylococcal enterotoxin B in monkeys. Appl. Microbiol. 1968, 16, 187-192.

81. Spiekermann, G.M.; Nagler-Anderson, C. Oral adminstration of the bacterial superantigen staphylococcal enterotoxin B induces activation and cytokine production by $\mathrm{T}$ cells in murine gutassociated lymphoid tissue. J. Immunol. 1998, 161, 5825-5831.

82. Alber, G.; Scheuber, P.H.; Reck, B.; Sailer-Kramer, B.; Hartmann, A.; Krammer, D.K. Role of substance $\mathrm{P}$ in immediate-type skin reactions induced by staphylococcal enterotoxin $\mathrm{B}$ in unsensitized monkeys. J. Allergy Clin. Immunol. 1998, 84, 880-885.

83. Hu, D.L.; Zhu, G.; Mori, F.; Omoe, K.; Okada, M.; Wakabayashi, K.; Kaneko, S.; Shinagawa, K.; Nakane, A. Staphylococcal enterotoxin induces emesis through increasing serotonin release in intestine and it is downregulated by cannabinoid receptor 1. Cell Microbiol. 2007, 9, 2267-2277.

84. Stiles, B.G.; Bavari, S.; Krakauer, T.; Ulrich, R.G. Toxicity of staphylococcal enterotoxins potentiated by lipopolysaccharide: major histocompatibility complex class II molecule dependency and cytokine release. Infect. Immun. 1993, 61, 5333-5338.

85. Sugiyama, H.; McKissic, E.M.; Bergdoll, M.S.; Heller, B. Enhancement of bacterial endotoxin lethality by staphylococcal enterotoxin. J. Infect. Dis. 1964, 4, 111-118.

86. Miethke, T.; Wahl, C.; Heeg, K.; Echtenacher, B.; Krammer, P.H.; Wagner, H. T cell-mediated lethal shock triggered in mice by the superantigen staphylococcal enterotoxin B: critical role of tumor necrosis factor. J. Exp. Med. 1992, 175, 91-98.

87. Miethke, T.; Wahl, C.; Heeg, K.; Echtenacher, B.; Krammer, P.H.; Wagner, H. Superantigen mediated shock: a cytokine release syndrome. Immunobiology 1993, 189, 270-284.

88. Sarawar, S.R.; Blackman, B.A.; Doherty, P.C. Superantigen shock in mice with an inapparent viral infection. J. Infect. Dis. 1994, 170, 1189-1194.

89. Chen, J.Y.; Qiao, Y.; Komisar, J.L.; Baze, W.B.; Hsu, I.C.; Tseng, J. Increased susceptibility to staphylococcal enterotoxin B intoxication in mice primed with actinomycin D. Infect. Immun. 1994, 62, 4626-4631.

90. Zhang, W.J.; Sarawar, S.; Nguyen, P; Daly, K.; Rehig, J.E.; Doherty, P.C.; Woodland, D.L.; Blackman, M.A. Lethal synergism between influenza infection and staphylococcal enterotoxin B in mice. J. Immunol. 1996, 157, 5049-5060.

91. Blank, C.; Luz, A.; Bendigs, S.; Erdmann, A.; Wagner, H.; Heeg, K. Superantigen and endotoxin synergize in the induction of lethal shock. Eur. J. Immunol. 1997, 27, 825-833.

92. Khan, A.A.; Priya, S.; Saha, B. IL-2 regulates SEB induced toxic shock syndrome in BALB/c mice. PLoS One 2009, 4, e8473.

93. Matthys, P.; Mitera, T.; Heremans, H.; Van Damme, J.; Billiau, A. Anti-gamma interferon and antiinterleukin-6 antibodies affect staphylococcal enterotoxin B-induced weight loss, hypoglycemia, and 
cytokine release in D-galactosamine-sensitized and unsensitized mice. Infect. Immun. 1995, 63, 1158-1164.

94. LeClaire, R.D.; Kell, W.; Bavari, S.; Smith, T.; Hunt, R.E. Protective effects of niacinamide in staphylococcal enterotoxin B induced toxicity. Toxicology 1996, 107, 69-81.

95. Krakauer, T.; Stiles, B.G. Pentoxifylline inhibits staphylococcal superantigen induced toxic shock and cytokine release. Clin. Diagn. Lab. Immunol. 1999, 6, 594-598.

96. Hale, M.L.; Margolin, S.B.; Krakauer, T., Roy, C.J.; Stiles, B.G. Pirfenidone blocks in vitro and in vivo effects of staphylococcal enterotoxin B. Infect. Immun. 2002, 70, 2989-2994.

97. Krakauer, T.; Buckley, M. Dexamethasone attenuates staphylococcal enterotoxin B-induced hypothermic response and protects mice from superantigen-induced toxic shock. Antimicrob. Agents Chemother. 2006, 50, 391-395.

98. Krakauer, T.; Buckley, M.; Fisher, D. Proinflammatory mediators of toxic shock and their Correlation to lethality. Mediators Inflamm. 2010, doi:10.1155/2010/517594.

99. Bean, A.G.; Freiberg, R.A.; Andrade, S.; Menon, S.; Zlotnik, A. Interleukin 10 protects mice against staphylococcal enterotoxin B-induced lethal shock. Infect. Immun. 1993, 61, 4937-4939.

100. Florquin, S.; Amraoui, Z.; Abramowicz, D.; Goldman, M. Systemic release and protective role of IL-10 in staphylococcal enterotoxin B-induced shock in mice. J. Immunol. 1994, 153, 2618-2623.

101. Sundstedt, A.; Hoiden, L.; Rosendahl, A.; Kalland, T.; van Rooijen, N.; Dohlsten, M. Immunoregulatory role of IL-10 during superantigen-induced-hyporesponsiveness in vivo. J. Immunol. 1997, 158, 180-186.

102. Miller, C.; Ragheb, J.; Schwartz, R. Anergy and cytokine-mediated suppression as distinct superantigen-induced tolerance mechanisms in vivo. J. Exp. Med.1999, 190, 53-64.

103. McCormack, J.E.; Callahan, J.E.; Kappler, J.; Marrack, P. Profound deletion of mature T cells in vivo by chronic exposure to endogenous superantigen. J. Immunol. 1993, 150, 3785-3792.

104. DaSilva, L.; Welcher, B.; Ulrich, R.; Aman, J.; David, C.S.; Bavari, S. Humanlike immune response of human leukocyte antigen-DR3 transgenic mice to staphylocococal enterotoxins: a novel model for superantigen vaccines. J. Infect. Dis. 2002, 185, 1754-1760.

105. Rajagopalan, G.; Sen, M.M.; David, C.S. In vitro and in vivo evaluation of staphylococcal superantigen peptide antagonists. Infect. Immun. 2004, 72, 6733-6737.

106. Roy, C.J.; Warfield, K.L.; Welcher, B.C.; Gonzales, R.F.; Larsen, T.; Hanson, J.; David, C.S.; Krakauer, T.; Bavari, S. Human leukocyte antigen-DQ8 transgenic mice: a model to examine the toxicity of aerosolized staphylococcal enterotoxin B. Infect. Immun. 2005, 73, 2452-2460.

107. Yeung, R.S.; Penninger, J.M.; Kundig, J.; Khoo, W.; Ohashi, P.S.; Kroemer, G.; Mak, T.W. Human CD4 and human major histocompatibility complex class II (DQ6) transgenic mice: supersensitivity to superantigen-induced septic shock. Eur. J. Immun. 1996, 26, 1074-1082.

108. Savransky, V.; Rostaphshov, V.; Pinelis, D.; Polotsky, Y.; Korolev, S.; Komisar, J.; Fegeding, K. Murine lethal toxic shock caused by intranasal administration of staphylococcal enterotoxin B. Toxicol. Pathol. 2003, 31, 373-378.

109. Stebbings, R.; Findlay, L.; Edwards, C.; Eastwood, D.; Bird, C.; North, D.; Mistry, Y.; Dilger, P.; Liefooghe, E.; Cludts, I.; et al. "Cytokine Storm" in the Phase I Trial of Monoclonal Antibody TGN1412: Better Understanding the Causes to Improve PreClinical Testing of Immunotherapeutics.

J. Immunol. 2007, 179, 3325-3331. 
110. Darenberg, J.; Soderquist, B.; Normark, B.H.; Norrby-Teglund, A. Differences in potency of intravenous polyspecific immunoglobulin $\mathrm{G}$ against streptococcal and staphylococcal superantigens: implications for therapy of toxic shock syndrome. Clin. Infect. Dis. 2004, 38, 836-842

111. Bavari, S.; Ulrich, R.G.; LeClaire, R.D. Cross-reactive antibodies prevent the lethal effects of Staphylococcus aureus superantigens. J. Infect. Dis. 1999, 180, 1365-1369.

112. Bavari, S.; Dyas, B.; Ulrich, R.G. Superantigen vaccines: a comparative study of genetically attenuated receptor-binding mutants of staphylococcal enterotoxin A. J. Infect. Dis. 1996, 174, 338-345.

113. Arad, G.; Levy, R.; Hillman, D.; Kaempfer, R. Superantigen antagonist protects against lethal shock and defines a new domain for T-cell activation. Nat. Med. 2000, 6, 414-421.

114. Visvanathan, K.; Charles, A.; Bannan, J.; Pugach, P.; Kashfi, K.; Zabriskie, J.B. Inhibition of bacterial superantigens by peptides and antibodies. Infect. Immun. 2001, 69, 875-884.

115. Wang, S.; Li, Y.; Xiong, H.; Cao, J. A broad-spectrum inhibitory peptide against staphylococcal enterotoxin superantigen SEA, SEB and SEC. Immunol. Lett. 2008, 121, 167-172.

116. Geller-Hong, E.; Möllhoff, M.; Shiflett, P.R.; Gupta, G. Design of chimeric receptor mimics with different TcRV $\beta$ isoforms: type-specific inhibition of superantigen pathogenesis. J. Biol. Chem. 2004, 279, 5676-5684.

117. Rasooly, R.; Do, P.M.; Friedman, M. Inhibition of biological activity of staphylococcal enterotoxin A (SEA) by apple juice and apple polyphenols. J. Agric. Food Chem. 2010, 58, 5421-5426.

118. Liu, D.; Liu, X.Y.; Robinson, D.; Burnett, C.; Jackson, C.; Seele, L.; Veach, R.A.; Downs, S.; Collins, R.D.; Ballard, R.W.; Hawiger, J. Suppression of staphylococcal enterotoxin B-induced toxicity by a nuclear import inhibitor. J. Biol. Chem. 2004, 279, 19239-19246.

119. Liu, D.; Zienkiewicz, J.; DiGiandomenico, A.; Hawiger, J. Suppression of acute lung inflammation by intracellular peptide delivery of a nuclear import inhibitor. Mol. Ther. 2009, 17, 796-802.

120. Tilahun, A.Y.; Theuer, J.E.; Patel, R.; David, C.S.; Rajagopalan, G. Detrimental Effect of the Proteasome Inhibitor, Bortezomib in Bacterial Superantigen- and Lipopolysaccharide-induced Systemic Inflammation. Mol. Ther. 2010, 18, 1143-1154.

121. Krakauer, T. A sensitive ELISA for measuring the adhesion of leukocytic cells to human endothelial cells. J. Immunol. Meth. 1994, 177, 207-213.

122. See, R.H.; Chow, A.W. Staphylococcal toxic shock syndrome toxin 1-induced tumor necrosis factor alpha and interleukin-1ß secretion by human peripheral blood monocytes and Tymphocytes is differentially suppressed by protein kinase inhibitors. Infect. Immun. 1992, 60, 3456-3459.

123. Krakauer, T. Suppression of endotoxin- and staphylococcal exotoxin-induced cytokines and chemokines by a phospholipase $\mathrm{C}$ inhibitor in human peripheral blood mononuclear cells. Clin. Diagn. Lab. Immunol. 2001, 8, 449-453.

124. Tschaikowsky, K.J.; Schmidt, J.; Meisner, M. Modulation of mouse endotoxin shock by inhibition of phosphatidylcholine-specific phospholipase C. J. Pharmacol. Exp. Therap. 1999, 285, 800-804.

125. Krakauer, T.; Buckley, M.; Issaq, H.J.; Fox, S.D. Rapamycin protects mice from staphylococcal enterotoxin B- induced toxic shock and blocks cytokine release in vitro and in vivo. Antimicrob. Agents Chemother. 2010, 54, 1125-1131.

126. Flechner, S.M. Sirolimus in kidney transplantation indications and practical guidelines: de novo sirolimus-based therapy without calcineurin inhibitors. Transplantation 2009, 97, S1-S6. 
127. Krakauer, T. Caspase inhibitors attenuate superantigen-induced inflammatory cytokines, chemokines and T-cell proliferation. Clin. Diagn. Lab. Immunol. 2004, 11, 621-624.

128. Krakauer, T.; Buckley, M. Doxycycline is anti-inflammatory and inhibits staphylococcal exotoxininduced cytokines and chemokines. Antimicrob. Agents Chemother. 2003, 47, 3630-3633.

129. Jo, D.; Liu, D.; Yao, S.; Collins, R.D.; Hawiger, J. Intracellular protein therapy with SOCS3 inhibits inflammation and apoptosis. Nat. Med. 2005, 11, 892-898.

(C) 2010 by the authors; licensee MDPI, Basel, Switzerland. This article is an Open Access article distributed under the terms and conditions of the Creative Commons Attribution license (http://creativecommons.org/licenses/by/3.0/). 